\section{Treatment modalities of necrobiosis lipoidica: a concise systematic review}

\author{
Amir Feily, Shadi Mehraban, \\ Department of Dermatology, Jahrom \\ University of Medical Sciences, Iran
}

\begin{abstract}
Necrobiosis lipoidica (NL) is a rare inflammatory granulomatous skin disorder closely associated with diabetes mellitus. The aim of this paper is to review and discuss all the treatment modalities proposed and tested for this disease. A systematic review of the existing literature was conducted to investigate all the available data and summarize all the clinical trials, case reports and original articles on NL. Two major databases (PubMed and Google Scholar) were used. We have examined about 70 articles. Numerous treatment modalities have been currently investigated to compare recalcitrant NL. Being rare, most of the studies regarding this disease are case reports or small-scale clinical trials. We have found that, in spite of plentiful investigations carried out during the years, there is no treatment modality that has proved to be utterly satisfactory in treating NL.
\end{abstract}

\section{Introduction}

Necrobiosis lipoidica (NL) is a rare inflammatory granulomatous skin disorder occurring as a result of collagen degeneration., ${ }^{1,2}$ Incidence rates are higher in women than men and in adults than children. ${ }^{3}$ NL typically presents at 30-40 years of age. ${ }^{4}$ It appears to be a discernible association between NL and diabetes mellitus (DM) in numerous studies, since Cohen et al. hold the view that more than fifty per cent of NL patients have concurrent diabetes; however diabetic patients also suffering from NL are less than one per cent. ${ }^{5}$ Two other studies, on the other hand, regard 80 and 60 per cent of NL patients to be diabetic, respectively. ${ }^{1,6}$ Regarding the substantial linkage between NL and DM and the unknown etiology of this disease, microangiopathy seems to play a notable role in the pathogenesis of NL. ${ }^{7}$ It characterized by well-circumscribed erythematous plaques mostly tends to involve the tibial region of the lower extremities. ${ }^{8,9}$ However, involvement of other sites of the body has also been proclaimed. ${ }^{7} \mathrm{NL}$ is a chronic relapsing-remitting disorder in which lesions are subject to ulcerations as a result of trauma, ${ }^{1}$ and it cannot always be differentiated from those of other inflammatory skin disorders. ${ }^{10}$ We have gone over about seventy articles and aim to discuss all the treatment modalities proposed and tested for NL in the literature as follows (a summary is reported in Supplementary Table S1).

\section{Corticosteroids}

\section{Systemic corticosteroids}

Taniguchi et al. scrutinized the efficacy of oral corticosteroids on the NL eruptions which led to their clinical cure. ${ }^{11}$ In a study of 6 patients with NL, administering systemic corticosteroids led to complete closure of all the ulcerations except for the atrophic ones. ${ }^{12}$ Plus treatment with prednisolone at a dose of 6 mg/day instigated improvement. ${ }^{13}$ Two other case reports of the same category, one by Tan et al. and the other one by Dwyer and Dick, ${ }^{14,15}$ have also been published. Furthermore, Bouhanick et al. presented a case report in which combination therapy with local corticosteroids and hyperbaric oxygen brought about remission of NL. ${ }^{16}$ Corticosteroids hereby can be regarded as an effective therapeutic agent for NL; however, their use in diabetics remains dubious considering the potential effect of destabilizing the control of DM. ${ }^{14}$

\section{Intralesional injection of corticos- teroids}

The efficacy of a Porto-jet injector with either triamcinolone acetonide or sterile normal saline was examined on five NL patients, three of which gained thorough resolution of the lesions and one only benefited from partial improvement. In spite of a high recurrence rate, reintroduction of the jet injector was advantageous. ${ }^{17}$ Asteroid bodies were identified in a case of NL in which administration of dipyridamole in company with intralesional triamcinolone for two months led to the utter abrogation of the lesions, which was persistent even after the cessation of therapy. ${ }^{18}$

\section{Topical corticosteroids}

Application of topical clobetasole propionate in two case studies proved to be effective. ${ }^{19}$

\section{Intravenous immunoglobulin and methylprednisolone}

In a study, intravenous immunoglobulin (IVIG) showed to be effective in overcoming the recalcitrant ulcers of $\mathrm{NL}$ in a female patient, however reintroduction of IVIG was of less efficacy. Receiving IV methylprednisolone also provoked improvement of the lesions. ${ }^{20}$
Correspondence: Amir Feily, Department of Dermatology, Honari Clinic, Motahari Street, Jahrom, Iran.

Tel.: +98.9177.204638.

E-mail: dr.feily@yahoo.com

Key words: Necrobisis lipoidica; treatment; review.

Contributions: the authors contributed equally.

Conflict of interest: the authors declare no potential conflict of interest.

Received for publication: 5 December 2014.

Revision received: 14 April 2015.

Accepted for publication: 26 April 2015.

This work is licensed under a Creative Commons Attribution NonCommercial 3.0 License (CC BYNC 3.0).

(C) Copyright A. Feily and S. Mehraban, 2015

Licensee PAGEPress, Italy

Dermatology Reports 2015; 7:5749

doi:10.4081/dr.2015.5749

\section{Pentoxifylline}

The role of Pentoxifylline as a treatment modality in NL was examined on a 20 -year old diabetic female with NL administered 3 times daily at a dose of $400 \mathrm{mg}$ provoking improvement after one month of therapy. A 2year follow-up revealed no recurrences on top of eradicating psychosomatic pressure from the patient. No side effects of treatment were noted. ${ }^{21}$ Noz et al. also presented a case of ulcerating NL which had failed to respond to topical and oral therapy with ASA but resolved dramatically with pentoxifylline..$^{22}$ The diagnosis of NL was established on the glans of the penis of a non-diabetic patient, which responded well to pentoxifylline. ${ }^{23}$ Trental therapy (pentoxifylline) in 17 patients with NL demonstrated beneficial effects both in terms of correction of the hematological parameters (e.g. blood viscosity, red cell aggregation and stability of red cell aggregates) and developing the skin status. ${ }^{24}$ Thus, pentoxifylline might be a profitable treatment option in NL. The recommended dosage is $400 \mathrm{mg}$ thrice daily continued for at least 6 months. ${ }^{21}$

\section{Anti tumor necrosis factor- alpha therapy}

\section{Infliximab}

An investigation evaluating the effect of intralesional infliximab on 3 NL patients illustrated utter abrogation of the lesions of $\mathrm{NL}$; 
however, follow up after therapy revealed recurrence of the disease. No prominent side effects were noted except for the painful injections. ${ }^{25}$ Also, an 84-year old type 1 diabetic woman with intractable NL illustrated marked response to the first intravenous infusion of infliximab, which led to complete clearance of the ulcers after three infusions. ${ }^{26}$

\section{Etanercept}

Marked amelioration was noted after administration of subcutaneous etanercept in the treatment of NL. ${ }^{27-29}$ However, treatment with subcutaneous adalimumab was not of any success. ${ }^{29}$

Based on the aforementioned studies, antiTNF-alpha drugs (etanercept/infliximab) can be advantageous in challenging recalcitrant ulcerating NL by both intralesional and intravenous routes of administration; however, additional investigations are required in order to ascertain further details regarding this treatment modality (dosage and treatment duration)..$^{27}$

\section{Skin grafting}

Several case reports have introduced skin grafting as a beneficial surgical intervention in severe ulcerating $\mathrm{NL}$ which has been applied by means of split-skin grafts and in company with porcine grafting in one case. ${ }^{30-33}$ Additionally, an investigation involving 7 cases of NL in Stanford university medical center asserted split-skin grafting to be of benefit with no following recurrence. ${ }^{34}$

\section{Ultraviolet A1 phototherapy}

Several studies have reported ultraviolet A1 (UVA1) phototherapy or topical psoralen plus ultraviolet A (PUVA) therapy to be beneficial in conquering recalcitrant $\mathrm{NL}$ unresponsive to other therapies, e.g. corticosteroids or surgery. ${ }^{2,35-38}$ A 68 -year old diabetic NL patient, in addition, demonstrated the same results undergoing topical PUVA therapy. ${ }^{39}$

\section{Cyclosporine}

Administration of systemic cyclosporine-A in two different case studies demonstrated promising results. ${ }^{1,40}$ Another study examining the effectiveness of cyclosporine on $2 \mathrm{NL}$ patients during a 4-month period revealed complete clearance of the ulcerations which also maintained after ceasing cyclosporine therapy. ${ }^{41}$ Furthermore, a cyclosporine regimen of $2.5 \mathrm{mg} / \mathrm{kg} /$ day for recalcitrant ulcerating NL proved to be of great value; however, recurrence was determined 3 months subsequent to discontinuing therapy which regressed after resuming cyclosporine. ${ }^{42}$ Smith introduced cyclosporine-A as an effective mode of treatment for NL as well. ${ }^{43}$

\section{Aspirin and dipyridamole (antiplatelet therapy)}

A double-blind, placebo-controlled trial randomized 14 NL patients into 2 groups receiving either aspirin and dipyridamole or a matching placebo, neither of which indicated any substantial improvements. ${ }^{44}$ On the contrary, the administration of acetylsalicylic acid and dipyridamole in $7 \mathrm{NL}$ patients disclosed improvement of the lesions owing to diminished thromboxane levels (which were raised in all the patients prior to therapy) in the author's point of view. ${ }^{45}$ In addition, Quimby et al. declared a low platelet survival time in NL patients extending back to normal in response to anti-platelet therapy; however, the response of the NL lesions to treatment diverged over a broad spectrum, from resolution to no perceptible improvement. ${ }^{46}$ Beck and Bjerring blamed low-dose acetylsalicylic acid (ASA) therapy for a notable decline in the skin blood flow of the center of the NL lesions measured by laser Doppler technique. ${ }^{47}$ Császár et al. proved the combination therapy of ASA and dipyridamole to be effective against the lesions of NL as well as reducing platelet aggregation. ${ }^{48}$ Last but not least, a double-blind controlled study indicated enlargement of the lesions of NL following both low-dose ASA and placebo therapy. ${ }^{49}$ According to the contrary outcomes of these studies, the efficacy of antiplatelet therapy remains to be seen.

\section{Topical tacrolimus}

Barth et al. used topical tacrolimus ointment in the treatment of a diabetic NL patient, also a known case of protein S-deficiency and antiphospholipid syndrome which led to considerable improvement. ${ }^{50}$ Another study also revealed substantial healing of the NL lesions following application of topical tocrolimus $0.1 \%$ maintaining after a 1 year follow-up. ${ }^{51}$

\section{Hyperbaric $\mathrm{O}_{2}$ therapy}

Brüngger investigated the effects of $100 \%$ oxygen on 9 non-diabetic NL patients, which brought about a significant increase in the oxygen pressure (Pc02) of the lesion, although noticeably lower than that of the normal skin as well as a dramatic upsurge in the PcCo2 level of the lesion borders. ${ }^{52}$ In another study, undergoing hyperbaric oxygen therapy ended up with utter clearance of all the ulcerations after 98 sessions. ${ }^{53}$

\section{Pancreas transplant}

A retrospective study involving NL patients with DM evaluated the effectiveness of pancreas versus kidney transplant determining whether reversal of DM can result in NL resolution. Pancreas transplantation with or without a kidney transplant contributed to the resolution of the NL lesions while kidney transplant alone was not of any success. ${ }^{54}$ Two case reports also described simultaneous pancreaskidney transplant and pancreas after kidney transplant to be profitable, leaving the patient free of lesions, respectively. ${ }^{8,55}$

\section{Fumaric acid esters}

A prospective study of 18 NL patients assessing the efficacy of fumaric acid esters (FAE) on NL demonstrated noteworthy recovery from the disease on top of an upsurge in the dermal density evaluated by $20-\mathrm{MHz}$ ultrasound. After a follow up period of 6 months, no recurrences were detected, suggesting FMA as an effective medication for NL. ${ }^{56}$ Also, clearance of the lesions of NL was reported in another study as a result of FMA therapy. ${ }^{57}$

\section{Pulsed dye laser}

Pulsed dye laser was examined as a treatment approach on a $4 \mathrm{~cm}$ NL lesion on the anterior surface of the leg of a non-diabetic patient who received 3 sessions of therapy. The outcomes were inconclusive as the left half of the lesion demonstrated signs of resolution, whereas the right upper quadrant of the lesion indicated negligible improvement. ${ }^{58}$ Furthermore, a study on a 23-year old diabetic NL patient receiving pulsed dye laser discloses this treatment modality to be ineffectual both at high and low fluencies as it could be detrimental to skin and therapeutically inconsequential, respectively. ${ }^{59}$ As it can clearly be seen, pulsed dye laser doesn't appear to be a safe and an effective treatment modality for NL. 


\section{Antimalarial agents}

Nguyen et al. demonstrated oral chloroquine to be beneficial in confronting NL. ${ }^{60}$ Also, improvement was noted after administration of antimalarial agents in 7 out of 8 patients. ${ }^{61}$

\section{Topical tretinoin}

Heymann corroborates efficacy of topical tretinoin in overcoming the atrophic lesions of NL. ${ }^{62}$ Also, favorable outcomes were achieved with the combination therapy of topical glucocorticoid and topical tretinoin in a 58-year old non diabetic female with 7 year history of NL. ${ }^{63}$

\section{Photodynamic therapy}

Photodynamic therapy with $632 \mathrm{~nm}$ of redlight and methyl aminolevulinate as a topical photosensitizer showed promising results in the treatment of a 60 year-old woman with progressive NL. ${ }^{64}$ However, it was effective in only 40 per cent of cases of a clinical trial. ${ }^{65}$

\section{Local granulocyte-macrophage colony stimulating factor}

Remes and Rönnemaa examined the efficacy of GM-CSF on two diabetic patients suffering from chronic refractory NL and concluded that this treatment modality is of benefit, for improvement was noted even after the $1^{\text {st }}$ episode of GM-CSF application ending in complete clearance of the lesions without recurrence after a 3 -year follow-up. ${ }^{66}$

\section{Clofazimine}

A clinical trial carried out on 10 patients suffering from NL assessed the efficacy of clofazimine administered at a daily dosage of $200 \mathrm{mg}$ P0. The trial was inconclusive as the clinical response to clofazimine varied in the patients from no improvement to a thorough remission from the lesions. The side effects were both negligible and reversible. ${ }^{67}$

\section{PROMOGRAN}

Studying the clinical efficacy of PROMOGRAN (a new protease modulating matrix) revealed utter resolution of an ulcer of NL after 8 weeks of therapy. ${ }^{68}$

\section{Benzoyl peroxide}

Application of 20\% topical benzoyl peroxide on the ulcers of NL prompted rapid improvement of the lesions. ${ }^{69}$

\section{Nicotinamide}

Treatment with high dose nicotinamide proved to be of efficacy in confronting NL. ${ }^{70}$

\section{Bovine collagen}

Treatment with topical bovine collagen led to significant improvement of the lesions of NL. ${ }^{71}$

\section{Thalidomide}

Treatment with thalidomide in a 51 year-old woman with NL left the patient free of lesions after 4 months of therapy. ${ }^{72}$

\section{Discussion and Conclusions}

As NL is a rare disease, there are not sufficient cases to perform effective prospective clinical trials, that is why most of the experiments carried out to date are case reports and small-scale clinical trials. Plus there are few comparative studies between different treatments of NL which lead us to the conclusion that despite the introduction of all these treatment modalities for NL, the therapy of choice remains an ongoing debate requiring further large-scale studies. But to sum up, we can proclaim the introduction of corticosteroids by various routes of administration (systemic, intralesional injection and topical) as a top priority in the treatment of NL despite the possibility of destabilizing the control of blood sugar in diabetic patients.

\section{References}

1. Aslan E, Körber A, Grabbe S, Dissemond J. Successful therapy of ulcerated necrobiosis lipoidica non diabeticorum with cyclosporine A. Hautarzt 2007;58:684-8.

2. De Rie MA, Sommer A, Hoekzema R, Neumann HA. Treatment of necrobiosis lipoidica with topical psoralen plus ultraviolet A. Br J Dermatol 2002;147:743-7.

3. Szabo RM, Harris GD, Burke WA. Necrobiosis lipoidica in a 9-year-old girl with new-onset type II diabetes mellitus. Pediatr Dermatol 2001;18:316-9.

4. Hammami H, Youssef S, Jaber K, et al. Perforating necrobiosis lipoidica in a girl with type 1 diabetes mellitus: a new case reported. Dermatol Online J 2008;14:11.

5. Cohen 0, Yaniv R, Karasik A, Trau H. Necrobiosis lipoidica and diabetic control revisited. Med Hypotheses 1996;46:348-50.

6. Fourati M, Marrak H, Fenniche S, et al. Necrobiosis lipoidica. Report of 4 cases and review of the literature. Tunis Med 2003;81:428-31.

7. Kota SK, Jammula S, Kota SK, et al. Necrobiosis lipoidica diabeticorum: a case-based review of literature. Indian J Endocrinol Metab 2012;16:614-20.

8. Gullo D, Latina A, Tomaselli L, et al. Healing of chronic necrobiosis lipoidica lesions in a type 1 diabetic patient after pancreas-kidney transplantation: a case report. J Endocrinol Invest 2007;30:259-62.

9. Stephens E, Robinson JA, Gottlieb PA. Becaplermin and necrobiosis lipoidicum diabeticorum: results of a case control pilot study. J Diabetes Complications 2001;15:55-6.

10. Mendoza V, Vahid B, Kozic H, Weibel S. Clinical and pathologic manifestations of necrobiosis lipoidica-like skin involvement in sarcoidosis. Joint Bone Spine 2007;74:647-9.

11. Taniguchi Y, Sakamoto T, Shimizu M. A case of necrobiosis lipoidica treated with systemic corticosteroid. J Dermatol 1993;20:304-7.

12. Petzelbauer P, Wolff K, Tappeiner G. Necrobiosis lipoidica: treatment with systemic corticosteroids. Br J Dermatol 1992;126:542-5.

13. Hocqueloux L, Gautier JF, Lebbe C, et al. [Ulcerated necrobiosis lipoidica associated with insulin-dependent diabetes mellitus. Beneficial effect of corticosteroid therapy by oral administration]. Presse Med 1996;25:25-7. [Article in French].

14. Tan E, Patel V, Berth-Jones J. Systemic corticosteroids for the outpatient treatment of necrobiosis lipoidica in a diabetic patient. J Dermatolog Treat 2007;18:246-8.

15. Dwyer CM, Dick D. Ulceration in necrobiosis lipoidica--a case report and study. Clin Exp Dermatol 1993;18:366-9.

16. Bouhanick B, Verret JL, Gouello JP, et al. Necrobiosis lipoidica: treatment by hyperbaric oxygen and local corticosteroids. Diabetes Metab 1998;24:156-9. 
17. Sparrow G, Abell E. Granuloma annulare and necrobiosis lipoidica treated by jet injector. Br J Dermatol 1975;93:85-9.

18. Jiquan S, Khalaf AT, Jinquan T, Xiaoming L. Necrobiosis lipoidica: a case with histopathological findings revealed asteroidbodies and was successfully treated with dipyridamole plus intralesional triamcinolone. J Dermatolog Treat 2008; 19:54-7.

19. Goette DK. Resolution of necrobiosis lipoidica with exclusive clobetasol propionate treatment. J Am Acad Dermatol 1990;22:855-6.

20. Batchelor JM, Todd PM. Treatment of ulcerated necrobiosis lipoidica with intravenous immunoglobulin andmethylprednisolone. J Drugs Dermatol 2012;11:256-9.

21. Basaria S, Braga-Basaria M. Necrobiosis lipoidica diabeticorum: response to pentoxiphylline. J Endocrinol Invest 2003;26: 1037-40.

22. Noz KC, Korstanje MJ, Vermeer BJ. Ulcerating necrobiosis lipoidica effectively treated with pentoxifylline. Clin Exp Dermatol 1993;18:78-9.

23. España A, Sánchez-Yus E, Serna MJ, et al. Chronic balanitis with palisading granuloma: an atypical genital localization of necrobiosis lipoidica responsive to pentoxifylline. Dermatology 1994;188:222-5.

24. Petrova GA, Levin GI. The blood rheological indices of patients with necrobiosis lipoidica. Vestn Dermatol Venerol 1989;12:45-8.

25. Barde C, Laffitte E, Campanelli A, et al. Intralesional infliximab in noninfectious cutaneous granulomas: three cases of necrobiosis lipoidica. Dermatology 2011; 222:212-6.

26. Hu SW, Bevona C, Winterfield L, et al. Treatment of refractory ulcerative necrobiosis lipoidica diabeticorum with infliximab: report of a case. Arch Dermatol 2009;145:437-9.

27. Suárez-Amor 0, Pérez-Bustillo A, RuizGonzález I, Rodríguez-Prieto MA. Necrobiosis lipoidica therapy with biologicals: an ulcerated case responding toetanercept and a review of the literature. Dermatology 2010;221:117-21.

28. Guedes R, Leite I, Baptista A, Rocha N. Ulcerative necrobiosis lipoidica: is there a place for anti-TNF $\alpha$ treatment? Case Rep Med 2012;2012:854738.

29. Kevin S Zhang MD, Long T, et al. Treatment of necrobiosis lipoidica with etanercept and adalimumab. Dermatol Online J 2009;15:12.

30. Youshock E, Beninson J. Necrobiosis lipoidica: treatment with porcine dressings, split-thickness skin graft sand pressure garments. A case report and review of treatment modalities. Angiology
1985;36:821-6.

31. Marr TJ, Traisman HS, Griffith BH, Schafer MA. Necrobiosis lipoidica diabeticorum in a juvenile diabetic: treatment by excision and skin grafting. Cutis 1977;19:348-50.

32. Owen CM, Murphy H, Yates VM. Tissueengineered dermal skin grafting in the treatment of ulcerated necrobiosis lipoidica. Clin Exp Dermatol 2001;26:176-8.

33. Imtiaz KE, Khaleeli AA. Squamous cell carcinoma developing in necrobiosis lipoidica. Diabet Med 2001;18:325-8.

34. Dubin BJ, Kaplan EN. The surgical treatment of necrobiosis lipoidica diabeticorum. Plast Reconstr Surg 1977;60:421-8.

35. Radakovic S, Weber M, Tanew A. Dramatic response of chronic ulcerating necrobiosis lipoidica to ultraviolet A1 phototherapy. Photodermatol Photoimmunol Photomed 2010;26:327-9.

36. Narbutt J, Torzecka JD, Sysa-Jedrzejowska A, Zalewska A. Long-term results of topical PUVA in necrobiosis lipoidica. Clin Exp Dermatol 2006;31:65-7.

37. Berking C, Hegyi J, Arenberger P, et al. Photodynamic therapy of necrobiosis lipoidica--a multicenter study of 18 patients. Dermatology 2009;218:136-9.

38. Beattie PE, Dawe RS, Ibbotson SH, Ferguson J. UVAl phototherapy for treatment of necrobiosis lipoidica. Clin Exp Dermatol 2006;31:235-8.

39. Köstler E, Wollina U. Ulcerated necrobiosis lipoidica: a combined treatment approach with dermatosurgery and PUVA. Int J Low Extrem Wounds 2003;2:243-5.

40. D'Argento V, Curatoli G, Filotico R, et al. Cyclosporin a in the treatment of necrobiosis lipoidica diabeticorum. J Dermatol Treatment 1997;8:123-5.

41. Darvay A, Acland KM, Russell-Jones R. Persistent ulcerated necrobiosis lipoidica responding to treatment with cyclosporin. Br J Dermatol 1999;141:725-7.

42. Stanway A, Rademaker M, Newman P. Healing of severe ulcerative necrobiosis lipoidica with cyclosporin. Australas J Dermatol 2004;45:119-22.

43. Smith K. Ulcerating necrobiosis lipoidica resolving in response to cyclosporine-A. Dermatol Online J 1997;3:2.

44. Statham B, Finlay AY, Marks R. A randomized double blind comparison of an aspirin dipyridamole combination versus a placebo in the treatment of necrobiosis lipoidica. Acta Derm Venereol 1981;61:270-1.

45. Heng MC, Song MK, Heng MK. Healing of necrobiotic ulcers with antiplatelet therapy. Correlation with plasma thromboxane levels. Int J Dermatol 1989;28:195-7.

46. Quimby SR Muller SA, Schroeter AL, et al. Necrobiosis lipoidica diabeticorum: platelet survival and response to platelet inhibitors. Cutis 1989;43:213-6.

47. Beck HI, Bjerring P. Skin blood flow in necrobiosis lipoidica during treatment with low-dose acetylsalicylic acid. Acta Derm Venereol 1988;68:364-5.

48. Császár A, Daróczy J, Szénási P, et al. [Necrobiosis lipoidica without diabetes mellitus (diagnostic and therapeutic possibilities)]. Orv Hetil 1989; 130:2141-5. [Article in Hungarian].

49. Beck HI, Bjerring P, Rasmussen I, et al. Treatment of necrobiosis lipoidica with low-dose acetylsalicylic acid. A randomized double-blind trial. Acta Derm Venereol 1985;65:230-4.

50. Barth D, Harth W, Treudler R, Simon JC. Topical tacrolimus in necrobiosis lipoidica. Hautarzt 2011;62:459-62.

51. Patsatsi A, Kyriakou A, Sotiriadis D. Necrobiosis lipoidica: early diagnosis and treatment with tacrolimus. Case Rep Dermatol 2011;3:89-93.

52. Brüngger A. [Transcutaneous measurement of oxygen and carbon dioxide pressure in necrobiosis lipoidica]. Hautarzt 1989;40:231-2. [Article in German].

53. Weisz G, Ramon Y, Waisman D Melamed Y. Treatment of necrobiosis lipoidica diabeticorum by hyperbaric oxygen. Acta Derm Venereol 1993;73:447-8.

54. Souza AD, El-Azhary RA, Gibson LE. Does pancreas transplant in diabetic patients affect the evolution of necrobiosis lipoidica? Int J Dermatol 2009;48:964-70.

55. Mazur MJ, Lowney AC, Prigoff J, et al. Resolution of long-standing necrobiosis lipoidica diabeticorum (NLD) lesion after restoration of euglycemia following successful pancreas after kidney (PAK) transplantation: a case report. Transplant Proc 2011;43:3296-8.

56. Kreuter A, Knierim C, Stücker M, et al. Fumaric acid esters in necrobiosis lipoidica: results of a prospective noncontrolledstudy. Br J Dermatol 2005;153:802-7.

57. Gambichler T, Kreuter A, Freitag M, et al. Clearance of necrobiosis lipoidica with fumaric acid esters. Germany Dermatol 2003;207:422-4.

58. Moreno-Arias GA, Camps-Fresneda A. Necrobiosis lipoidica diabeticorum treated with the pulsed dye laser. J Cosmet Laser Ther 2001;3:143-6.

59. Currie CL, Monk BE. Pulsed dye laser treatment of necrobiosis lipoidica: report of a case. J Cutan Laser Ther 1999;1:23941.

60. Nguyen K, Washenik K, Shupack J. Necrobiosis lipoidica diabeticorum treated with chloroquine. J Am Acad Dermatol 2002;46:S34-6.

61. Durupt F, Dalle S, Debarbieux S, et al. Successful treatment of necrobiosis lipoidica with antimalarial agents. Arch 
Dermatol 2008;144:118-9.

62. Heymann WR. Necrobiosis lipoidica treated with topical tretinoin. Cutis 1996;58:534.

63. 0'Reilly K, Chu J, Meehan S, et al. Necrobiosis lipoidica. Dermatol Online J 2011;17:18.

64. Heidenheim M1, Jemec GB. Successful treatment of necrobiosis lipoidica diabeticorum with photodynamic therapy. Arch Dermatol 2006;142:1548-50.

65. Berking C, Hegyi J, Arenberger P, et al. Photodynamic therapy of necrobiosis lipoidica: a multicenter study of 18 patients. Denmark. Dermatol
2009;218:136-9.

66. Remes K, Rönnemaa T. Healing of chronic leg ulcers in diabetic necrobiosis lipoidica with local granulocyte-macrophage colony stimulating factor treatment. J Diabetes Complications 1999;13:115-8.

67. Mensing H. Clofazimine--therapeutic alternative in necrobiosis lipoidica and granuloma anulare. Hautarzt 1989;40:99103.

68. Omugha N, Jones AM. The management of hard-to-heal necrobiosis with PROMOGRAN. Br J Nurs 2003;12:S14-20.

69. Hanke CW, Bergfeld WF. Treatment with benzoyl peroxide of ulcers on legs within lesions of necrobiosis lipoidica diabeticorum. J Dermatol Surg Oncol 1978;4:701-4.

70. Handfield-Jones S, Jones S, Peachey R. High dose nicotinamide in the treatment of necrobiosis lipoidica. Br J Dermatol 1988;118:693-6.

71. Spenceri EA, Nahass GT. Topically applied bovine collagen in the treatment of ulcerative necrobiosis lipoidica diabeticorum. Arch Dermatol 1997;133:817-9.

72. Kukreja T, Petersen J. Thalidomide for the treatment of refractory necrobiosis lipoidica. Arch Dermatol 2006;142:20-2. 